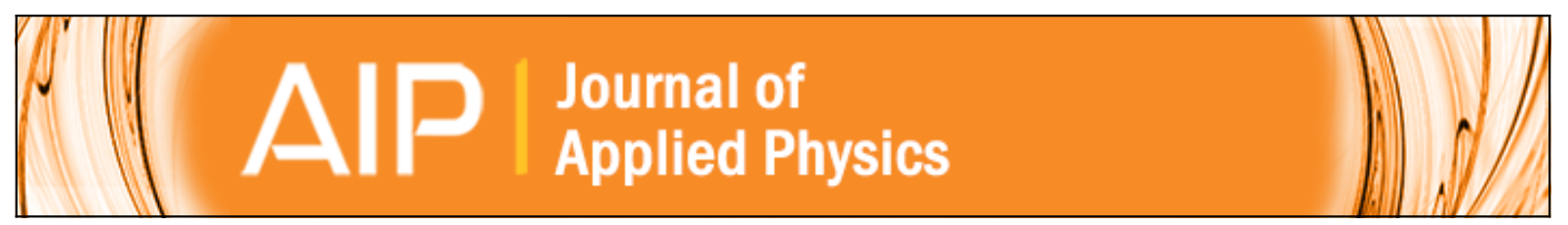

\title{
Electric field-controlled magnetization in bilayered magnetic films for magnetoelectric memory
}

Wei-Gang Yang, Nicola A. Morley, and W. Mark Rainforth

Citation: Journal of Applied Physics 118, 034102 (2015); doi: 10.1063/1.4926875

View online: http://dx.doi.org/10.1063/1.4926875

View Table of Contents: http://scitation.aip.org/content/aip/journal/jap/118/3?ver=pdfcov

Published by the AIP Publishing

\section{Articles you may be interested in}

Phase modulated magnetoelectric delta-E effect sensor for sub-nano tesla magnetic fields

Appl. Phys. Lett. 107, 152402 (2015); 10.1063/1.4932575

Large E-field tunability of magnetic anisotropy and ferromagnetic resonance frequency of co-sputtered Fe50Co50-B film

J. Appl. Phys. 117, 17D702 (2015); 10.1063/1.4906752

Amorphous FeCoSiB for exchange bias coupled and decoupled magnetoelectric multilayer systems: Realstructure and magnetic properties

J. Appl. Phys. 116, 134302 (2014); 10.1063/1.4896662

Electric field control of magnetism in FePd/PMN-PT heterostructure for magnetoelectric memory devices J. Appl. Phys. 115, 024903 (2014); 10.1063/1.4861618

Direct measurements of field-induced strain at magnetoelectric interfaces by grazing incidence $\mathrm{x}$-ray diffraction Appl. Phys. Lett. 102, 011601 (2013); 10.1063/1.4773358

\section{AIP $\left.\right|_{\text {APL Photonics }}$}

APL Photonics is pleased to announce Benjamin Eggleton as its Editor-in-Chief

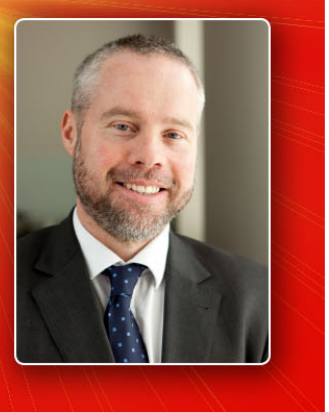




\title{
Electric field-controlled magnetization in bilayered magnetic films for magnetoelectric memory
}

\author{
Wei-Gang Yang, Nicola A. Morley, and W. Mark Rainforth ${ }^{\text {a) }}$ \\ Department of Materials Science and Engineering, University of Sheffield, Sheffield S1 3JD, United Kingdom
}

(Received 13 April 2015; accepted 5 July 2015; published online 15 July 2015)

\begin{abstract}
Bilayered magnetic films $\left(\mathrm{Co}_{50} \mathrm{Fe}_{50}(\mathrm{CoFe}) /\right.$ Metglas) were RF sputtered on both (001)-oriented and (011)-oriented PMN-PT (lead magnesium niobate-lead titanate) substrates. Electric field-controlled magnetization changes were observed in all these samples: $65 \mathrm{~nm} \mathrm{CoFe} / 24 \mathrm{~nm}$ Metglas/(001) PMN-PT, $65 \mathrm{~nm} \mathrm{CoFe} / 24 \mathrm{~nm}$ Metglas/(011) PMN-PT, and $30 \mathrm{~nm} \mathrm{CoFe} / 12 \mathrm{~nm}$ Metglas/(011) PMN-PT. The maximum magnetic remanence ratio change $\left(\Delta \mathrm{M}_{\mathrm{r}} / \mathrm{M}_{\mathrm{s}}\right)$ was $46 \%$ for $\mathrm{CoFe} / \mathrm{Metglas} /$ (001) PMN-PT. In this heterostructure, the electric-field created two new non-volatile switchable remanence states and the as-grown remanence state was altered permanently. High-resolution transmission electron microscopy images show a sharp and smooth interface between Metglas and substrate and conversely a rougher interface was observed between Metglas and CoFe films. In the $30 \mathrm{~nm} \mathrm{CoFe} / 12 \mathrm{~nm}$ Metglas/(011) PMN-PT sample, a large $\Delta \mathrm{M}_{\mathrm{r}} / \mathrm{M}_{\mathrm{s}}$ of $80 \%$ along the [100] direction was measured, while the $\Delta \mathrm{M}_{\mathrm{r}} / \mathrm{M}_{\mathrm{s}}$ along the [01-1] direction was $60 \%$ at the applied electric field of $5 \mathrm{kV} / \mathrm{cm}$, corresponding to a giant magnetoelectric coupling constant $\alpha=\mu_{\mathrm{o}} \Delta \mathrm{M}_{\mathrm{r}} / \mathrm{E}=2.9 \times 10^{-6} \mathrm{~s} / \mathrm{m}$. C 2015 AIP Publishing LLC. [http://dx.doi.org/10.1063/1.4926875]
\end{abstract}

\section{INTRODUCTION}

Magnetoelectric ${ }^{1}$ random access memory (MERAM), i.e., electric field (E-field)-controlled magnetic random access memory (MRAM) ${ }^{2}$ has been proposed to drastically reduce the write energy in the recording process, which is important for further miniaturization. The MERAM element $^{3,4}$ combines bilayered ferromagnetic films (the free layer and pinned layer in a spin-valve structure) with a ferroelectric layer based on the giant magnetoresistance (GMR) effect or tunneling magnetoresistance (TMR) effect. Recently, many publications ${ }^{5-13}$ have studied the E-fieldcontrolled magnetization change in the multiferroic heterostructures, ${ }^{14-16}$ which consist of a monolayer magnetic film and ferroelectric ${ }^{17}$ layer. However, much less studies have been done on the bilayered ferromagnetic films.

Liu et $a .^{18}$ investigated E-field-controlled magnetization of the free layer $\mathrm{Co}$ in $\mathrm{FeMn} / \mathrm{Ni}_{80} \mathrm{Fe}_{20} / \mathrm{Cu} / \mathrm{Co} / \mathrm{PZN}-\mathrm{PT}$ heterostructure, where a magnetoresistance (MR) change was also demonstrated based on GMR. A minimum and maximum MR were measured when magnetic alignment of adjacent $\mathrm{Co}$ and NiFe layers was parallel and antiparallel, respectively. However, the magnetization and magnetic anisotropy changes vanished and the MR returned to the initial state after the E-field was removed. In other words, two different stable magnetization states at zero magnetic and electric field did not exist and therefore the device would only work if a constant E-field was applied for one of the two magnetization arrangements. This is clearly not practically useful for novel memory and logic device applications. Recently, non-volatile magnetization changes induced by the E-field have been demonstrated in monolayer magnetic films' multiferroic heterostructures, such as $\mathrm{CoPd} / \mathrm{PZT},{ }^{12} \mathrm{Ni} /$

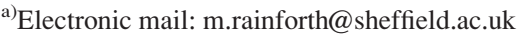

PZT ${ }^{19} \mathrm{FeGe} / \mathrm{BiScO}_{3}-\mathrm{PbTiO}_{3},{ }^{20} \mathrm{Ni} / \mathrm{PMN}-\mathrm{PT},{ }^{21}$ and $\mathrm{Co} /$ PMN-PT. ${ }^{22} \mathrm{Wu}$ et al. $^{21}$ demonstrated the giant non-volatile magnetic remanence change $\left(\Delta \mathrm{M}_{\mathrm{r}} / \mathrm{M}_{\mathrm{s}}\right)$ of $50 \%$ in $\mathrm{Ni} /(011)$ PMN-PT heterostructures because a large remanent strain of $+1220 \mathrm{ppm}$ was created when the E-field was only changed within a specific small regime $(-0.14 \mathrm{MV} / \mathrm{m}-0.6 \mathrm{MV} / \mathrm{m})$. Yang $\mathrm{et} \mathrm{al}^{22}$ reported the reversible and non-volatile rotation of magnetization in the $\mathrm{Co} /(001)$ PMN-PT heterostructures. The magnetic easy-axis (MEA) of the circular Co film rotated gradually from the direction [010] to [100] and remained stable after the E-field was removed. The experimental results were attributed to the giant strain from a phase transition from rhombohedral to monoclinic in the PMN-PT when the E-field was applied. In addition, the monoclinic phase induced by the E-field could remain stable after the Efield was removed. ${ }^{22}$

Therefore, the next step is to demonstrate the E-fieldcontrolled non-volatile $\Delta \mathrm{M}_{\mathrm{r}} / \mathrm{M}_{\mathrm{s}}$ in bilayered ferromagnetic films. In this study, we demonstrate a new non-volatile magnetization change in bilayered $\mathrm{Co}_{50} \mathrm{Fe}_{50}(\mathrm{CoFe}) / \mathrm{Metglas}$ magnetic films on (001)-oriented PMN-PT where the asgrown magnetic anisotropy is altered permanently. When an E-field from $-6 \mathrm{kV} / \mathrm{cm}$ to $0 \mathrm{kV} / \mathrm{cm}$ is applied, the MEA is along the [100] direction of the PMN-PT, while when the opposite E-field from $+6 \mathrm{kV} / \mathrm{cm}$ to $0 \mathrm{kV} / \mathrm{cm}$ is applied, the MEA becomes along the [010] direction of the PMN-PT. Two stable distinct magnetization states induced by the E-field are obtained, essential for the applications of the novel memory and logic devices. In this study, we also demonstrate the large magnetization changes in CoFe/Metglas/ (011) PMN-PT heterostructures. The bilayered films also show excellent soft magnetic properties with high magnetostriction due to an extremely low coercive field $\left(\mathrm{H}_{\mathrm{c}} \approx 1.13 \mathrm{Oe}\right.$ (Ref. 23$)$ or $\left.0.09 \mathrm{kA} / \mathrm{m}\right)$ and relatively high magnetostriction constant $(\lambda \approx 35 \mathrm{ppm}$ (Ref. 23)) for the 
Metglas layer. The $\mathrm{H}_{\mathrm{c}}$ of CoFe film on (001) PMN-PT substrate is reduced from $\sim 4 \mathrm{kA} / \mathrm{m}$ to $\sim 1 \mathrm{kA} / \mathrm{m}$ when the Metglas layer is introduced. Meanwhile, the $\lambda$ is also improved from $35 \pm 5 \mathrm{ppm}$ to $60 \pm 10 \mathrm{ppm}$. Such bilayered films with low $\mathrm{H}_{\mathrm{c}}$ and high $\lambda$ provide great opportunities to switch magnetization direction under a low energy level in the magnetoelectric (ME) heterostructures. In addition, a large lattice mismatch $(\sim 28.9 \%)$ between the $\mathrm{CoFe}$ $\left(\mathrm{a}_{\mathrm{CoFe}}=2.858 \AA\right.$ (Ref. 24)) and the PMN-PT ( $\mathrm{a}_{\mathrm{PMN}-\mathrm{PT}}$ $=4.021 \AA$ (Ref. 25)) may induce a weak tensile strain in the film layer. The introduction of the amorphous layer should eliminate the potential strain, which may be helpful to the magnetoelastic coupling.

\section{EXPERIMENTS}

Bilayered ferromagnetic films of $\mathrm{CoFe} / \mathrm{Metglas}$ were directly deposited onto both (001) and (011)-oriented $\left[\mathrm{Pb}\left(\mathrm{Mg}_{1 / 3}\right.\right.$ $\left.\left.\mathrm{Nb}_{2 / 3}\right) \mathrm{O}_{3}\right]_{(1-\mathrm{x})}-\left[\mathrm{PbTiO}_{3}\right]_{\mathrm{x}}(\mathrm{PMN}-\mathrm{PT}, \mathrm{x} \approx 0.28)$ substrates without breaking the vacuum by RF sputtering in a Nordiko NM2000 RF deposition system. The targets used were polycrystalline $\mathrm{Co}_{50} \mathrm{Fe}_{50}$ alloy and amorphous METGLAS ${ }^{\circledR}$ 2605SC foil with the $\mathrm{Fe}_{81} \mathrm{~B}_{13.5} \mathrm{Si}_{3.5} \mathrm{C}_{2}$ composition. The sputtering power, working pressure, and base pressure were $75 \mathrm{~W}$, $5.0 \pm 0.1 \mathrm{mTorr}$, and $1.2 \pm 0.2 \times 10^{-3}$ mTorr, respectively. The growth temperature was almost room temperature. The (001)-oriented PMN-PT $(5 \mathrm{~mm}[100] \times 5 \mathrm{~mm}$ [010] $\times 0.4 \mathrm{~mm}$ [001]) provided biaxial strains with in-plane piezoelectric coefficient of $d_{31}=-1000 \mathrm{pC} / \mathrm{N},{ }^{26}$ while the (011)-oriented PMNPT $(10 \mathrm{~mm}[01-1] \times 5 \mathrm{~mm} \mathrm{[100]} \times 0.5 \mathrm{~mm}$ [011]) had the anisotropic strains with in-plane piezoelectric coefficients of $d_{31}=-1500 \sim-2000 \mathrm{pC} / \mathrm{N}$ and $d_{32}=500-700 \mathrm{pC} / \mathrm{N}$ reported by the supplier. The substrates were polled at an E-field of $5 \mathrm{kV} / \mathrm{cm}$ for $10 \mathrm{~min}$ through the thickness before being used, which is to ensure the substrate has a converse piezoelectric effect, i.e., the E-field is able to induce a strain in the substrate. Magneto-optical Kerr effect (MOKE) measurements were used to investigate magnetic properties when a series of dc E-fields were applied to the substrates, as shown in the schematic in Fig. 1. The normalized remanent magnetization $\left(\mathrm{M}_{\mathrm{r}} / \mathrm{M}_{\mathrm{s}}\right)$ and anisotropic field $\left(\mathrm{H}_{\mathrm{k}}\right)$ were taken from the magnetic hysteresis loops. The $H_{k}$ was taken at the $M / M_{s}=1$. The effective saturation magnetostriction constants $(\lambda)$ were measured using a technique ${ }^{27}$ based on the Villari effect. Cross-sectional transmission electron microscopy (TEM) specimens were prepared by Focused Ion Beam (FIB) in FEI Quanta 200 3D and observed on both FEI Tecnai T20 and Jeol $2010 \mathrm{~F}$ operating at $200 \mathrm{kV}$.

\section{RESULTS AND DISCUSSION}

To understand the microstructure of the magnetic films and interfaces in the heterostructure, cross-sectional TEM was undertaken. Fig. 2(a) gives a bright field TEM image of the cross-section, while (b) and (c) give high-resolution TEM (HRTEM) images and selected area electron diffraction (SAED) pattern (d). The interface between the amorphous Metglas film and the PMN-PT (Fig. 2(b)) is welldefined and smooth, while that between the Metglas film and the CoFe film (Fig. 2(c)) is much rougher. The CoFe

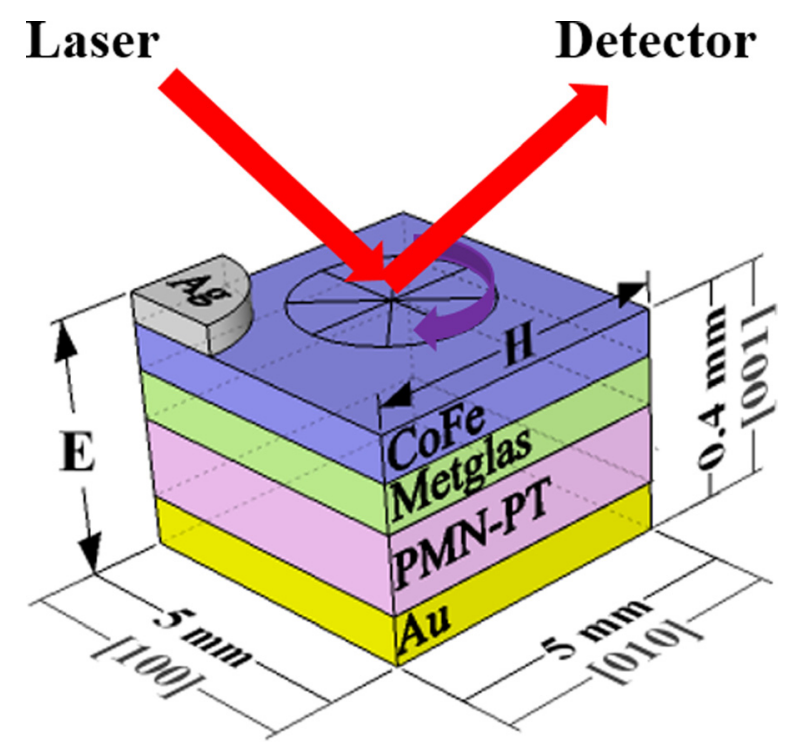

FIG. 1. A schematic (not to scale) of $65 \mathrm{~nm} \mathrm{CoFe} / 24 \mathrm{~nm}$ metglas $/ 400 \mu \mathrm{m}$ (001) PMN-PT heterostructure. Magnetic properties were measured by MOKE system. Magnetic field $(\mathrm{H})$ was fixed and applied in plane, while the E was applied through the thickness. The sample was measured with rotating within $360^{\circ}$.

film still shows a polycrystalline structure with an out-of plane [110] texture even on the amorphous layer, as shown in Fig. 2(d).

Fig. 3 shows a strong ME coupling in all samples of both (001)-oriented and (011)-oriented PMN-PT substrates. For the [100] crystallographic direction (Figs. 3(b), 3(d), and 3(f)), when the applied E-field increases, the $\mathrm{M}_{\mathrm{r}} / \mathrm{M}_{\mathrm{s}}$ reduces and $\mathrm{H}_{\mathrm{k}}$ increases. In contrast, $\mathrm{M}_{\mathrm{r}} / \mathrm{M}_{\mathrm{s}}$ increases and $\mathrm{H}_{\mathrm{k}}$ reduces along either direction [010] (Fig. 3(a)) or [01-1] (Fig. 3(e)) due to a compressive strain along [100] and positive magnetostriction constant $(\lambda)$. As shown in Fig. 3(c), the $\lambda$ of the bilayered magnetic films increases from $35 \pm 5 \mathrm{ppm}$ to $60 \pm 10 \mathrm{ppm}$ when the Metglas thickness is greater than $6 \mathrm{~nm}$, which may be attributed to a negative interface effect ${ }^{28}$ removed by Metglas underlayer between $\mathrm{CoFe}$ and substrate. In addition, the $\lambda$ of the bilayered magnetic films $(65 \mathrm{~nm}$ $\mathrm{CoFe} / 24 \mathrm{~nm}$ Metglas and $30 \mathrm{~nm} \mathrm{CoFe} / 12 \mathrm{~nm}$ Metglas) is similar at around $60 \mathrm{ppm}$. However, the thinner bilayered films show stronger ME coupling than the thicker bilayered films, as shown in Figs. 3(d)-3(f), which is consistent with the previous investigation ${ }^{29}$ on the effect of magnetic layer thickness on ME coupling. Reducing the magnetic layer thickness can cause the reduction in the strain relaxation and thus increase the ME coupling. In the $30 \mathrm{~nm} \mathrm{CoFe} / 12 \mathrm{~nm}$ Metglas/(011) PMN-PT sample, a maximum $\Delta \mathrm{M}_{\mathrm{r}} / \mathrm{M}_{\mathrm{s}}$ is measured along the [100] direction of $80 \%$ at the applied E-field of $10 \mathrm{kV} / \mathrm{cm}$, while along the [01-1] direction $\Delta \mathrm{M}_{\mathrm{r}} / \mathrm{M}_{\mathrm{s}}$ is $60 \%$ at the applied E-field of only $5 \mathrm{kV} / \mathrm{cm}$, corresponding to a giant ME coupling constant ${ }^{30} \alpha=\mu_{\mathrm{o}} \Delta \mathrm{M}_{\mathrm{r}} / \mathrm{E}=2.9 \times 10^{-6} \mathrm{~s} / \mathrm{m}$, which is much larger than $1.6 \times 10^{-7} \mathrm{~s} / \mathrm{m},{ }^{31} 4.55 \times 10^{-7} \mathrm{~s} / \mathrm{m}$ (Ref. 7), and $8 \times 10^{-7} \mathrm{~s} / \mathrm{m}$ (Ref. 29) reported in monolayer magnetic film systems. In addition, it is noted that the $\mathrm{H}_{\mathrm{c}}$ is increased significantly by a factor of three when the E-field of $10 \mathrm{kV} / \mathrm{cm}$ was applied to the $65 \mathrm{~nm} \mathrm{CoFe} / 24 \mathrm{~nm}$ Metglas/ (011) PMN-PT sample. For (001)-oriented PMN-PT's 

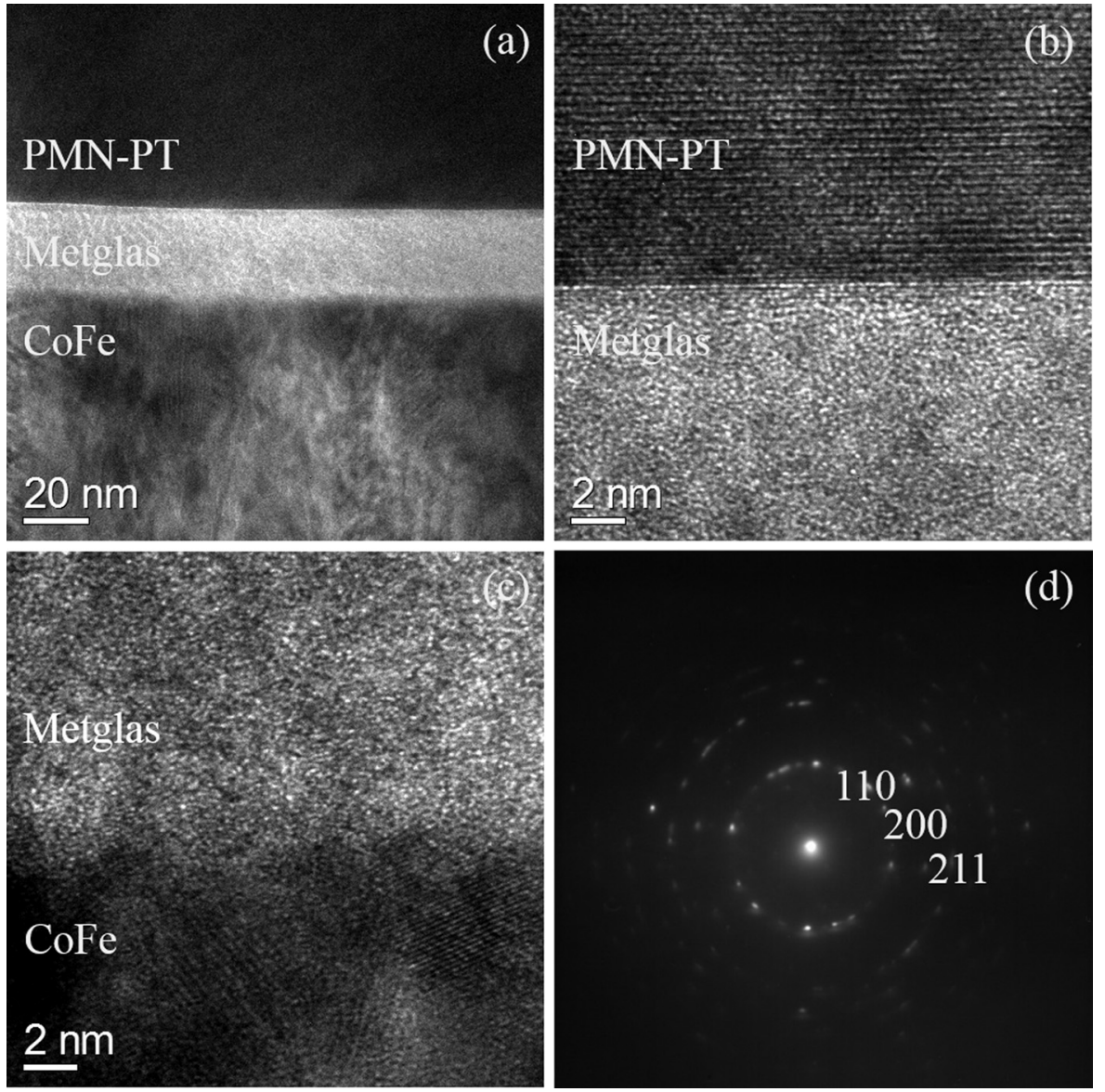

FIG. 2. Cross-sectional bright field TEM image (a) and HRTEM images (b) and (c) of the CoFe/Metglas/PMNPT heterostructure. The SAED pattern (d) of $\mathrm{CoFe}$ film. heterostructure, more detailed magnetization change induced by the E-field is discussed as follows in Figs. 4-7.

Fig. 4 shows an angular dependence of the $\mathrm{M}_{\mathrm{r}} / \mathrm{M}_{\mathrm{s}}$ and $\mathrm{H}_{\mathrm{k}}$ in the $65 \mathrm{~nm} \mathrm{CoFe} / 24 \mathrm{~nm}$ Metglas/(001) PMN-PT sample. The $0^{\circ}$ corresponds to the [010] direction of PMN-PT substrate. The magnetic anisotropy in both $M_{r} / M_{s}$ and $H_{k}$ is weak without the applied E-field. With the increasing E-field to $+3 \mathrm{kV} / \mathrm{cm}$ and $+6 \mathrm{kV} / \mathrm{cm}$, the anisotropy is steadily strengthened. At the maximum E-field of $+6 \mathrm{kV} / \mathrm{cm}$, the bilayered magnetic films show a uniaxial anisotropy. The magnetization becomes easy along [010], while it becomes hard along [100] due to the E-field inducing positive effective $H_{k}$ along [100] and negative effective $H_{k}$ along [010]. The results are consistent with the previous reports in $\mathrm{CoPd} /$ (001) PMN-PT system ${ }^{29}$ and $\mathrm{NiFe}_{2} \mathrm{O}_{4} /(001)$ PMN-PT system. ${ }^{5}$ Similarly, for $\mathrm{Fe}_{3} \mathrm{O}_{4} / \mathrm{PZT}\left(d_{31}=d_{32}<0\right)$ system, ${ }^{6}$ a large change $\mathrm{M}_{\mathrm{r}}$ of $44 \%$ was also observed when external magnetic field was along in-plane direction. However, the reason why the in-plane biaxial strain can induce the large in-plane anisotropy change was not explained in these reports. Here, we think the magnitude of the compressive strains along [100] and [010] should be different, which leads a total compressive strain along a sole direction. Therefore, the uniaxial anisotropy is induced by the biaxial compressed strains ${ }^{25}$ with an estimated total compressive strain $(\Delta \varepsilon=-0.07 \%$ (Refs. 5 and 32)) along [100] at applied E-field of $6 \mathrm{kV} / \mathrm{cm}$.

Figs. 5(a) and 5(b) show the electrical dependence of the $\mathrm{M}_{\mathrm{r}} / \mathrm{M}_{\mathrm{s}}$ and $\mathrm{H}_{\mathrm{k}}$ along [010] direction with two opposite sweeping fields from $+6 \mathrm{kV} / \mathrm{cm}$ to $-6 \mathrm{kV} / \mathrm{cm}$ and from $-6 \mathrm{kV} / \mathrm{cm}$ to $+6 \mathrm{kV} / \mathrm{cm}$, respectively. The arrows indicate the direction of the E-field sweeping. The changes in $M_{r} / M_{s}$ and $\mathrm{H}_{\mathrm{k}}$ show typical "butterfly" curves dependence on the Efield, which resembles curves of piezoelectric strains against the E-field change, ${ }^{22}$ suggesting that piezoelectric strains induce strong ME coupling through the inverse magnetostrictive effect. The sharp valleys and peaks of the curves in Fig. 5 are caused by a large nonlinear strain jump below the ferroelectric coercive field $\left(\mathrm{E}_{\mathrm{c}} \approx 2 \mathrm{kV} / \mathrm{cm}\right)$, which is attributed to the reorientation of non- $180^{\circ}$ ferroelectric polarization. $^{21}$ The comparable change ratios of $\mathrm{M}_{\mathrm{r}} / \mathrm{M}_{\mathrm{s}}, \mathrm{H}_{\mathrm{k}}$, and $\mathrm{H}_{\mathrm{c}}$ to the initial values are $71 \%, 76 \%$, and $69 \%$, respectively. In addition, a non-volatile magnetization change is demonstrated, as shown in Fig. 5(a). Two distinct bistable magnetization states " 1 " and " 2 " are created by the different direction of the sweeping E-field and also can be reversibly switched by the E-field. Therefore, these can be directly read out electrically by magnetotransport measurements, which demonstrate the potential for the MERAM memory cell application. A short voltage impulse can change the magnetization without continuous E-field needed and an opposite voltage signal can return the magnetization to the other state. This may be typically utilized to develop fast, low-power and high-density information storage device by E-field instead of the H-field generated by bulky and energyconsumed electromagnets.

Figs. 6(a) and 6(b) show the electrical dependence of $\mathrm{M}_{\mathrm{r}} / \mathrm{M}_{\mathrm{s}}$ along [100] with the different E-field sweeping 

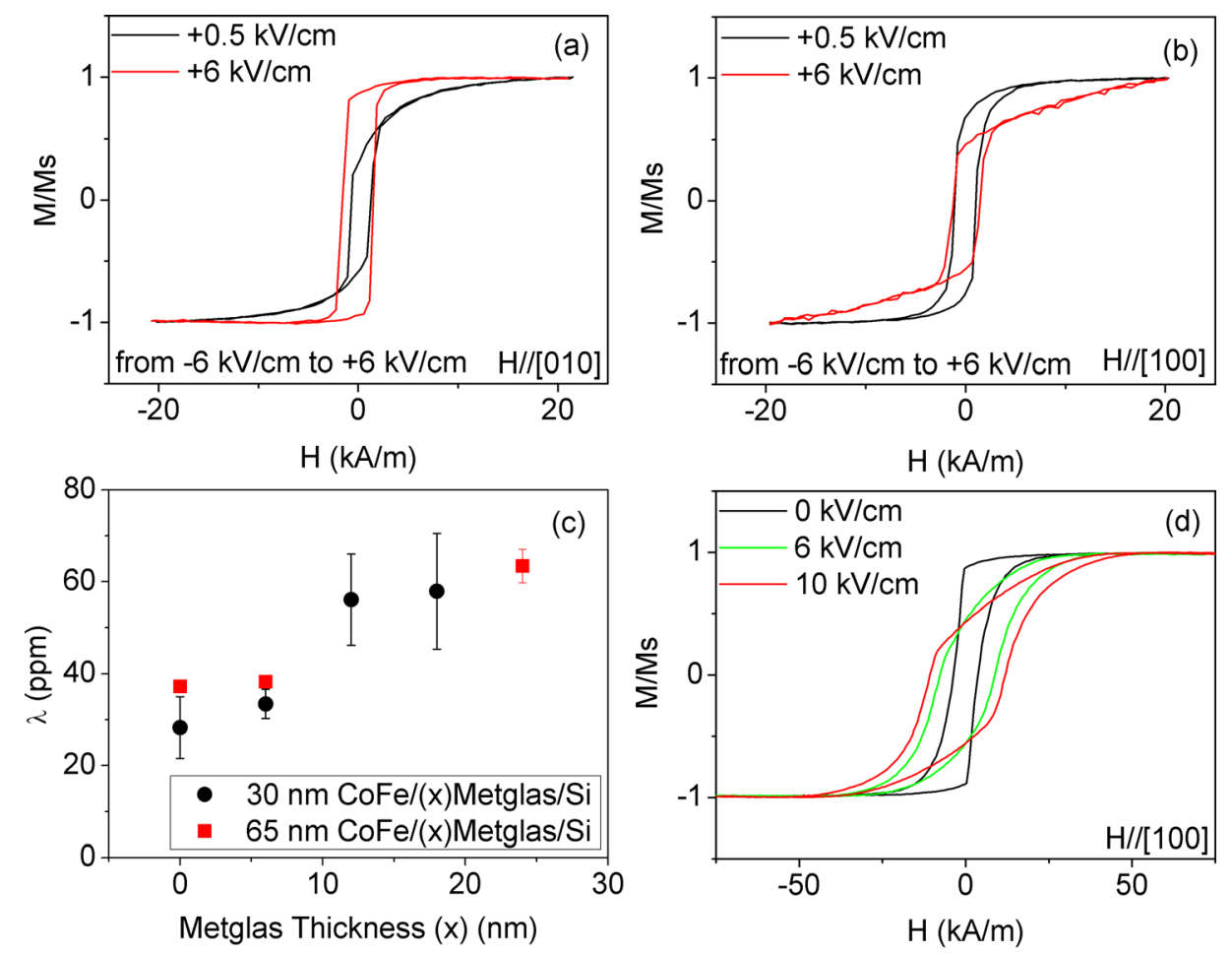

FIG. 3. Electric-field dependence of magnetic hysteresis loops in $65 \mathrm{~nm}$ CoFe/24nm Metglas/(001) PMN-PT heterostructure (a) and (b), in $65 \mathrm{~nm}$ $\mathrm{CoFe} / 24 \mathrm{~nm}$ Metglas/(011) PMN-PT heterostructure (d) and in $30 \mathrm{~nm} \mathrm{CoFe} /$ $12 \mathrm{~nm}$ Metglas/(011) PMN-PT heterostructure (e) and (f). The variation of effective saturation magnetostriction constants $(\lambda)$ with Metglas thickness (x) (c).
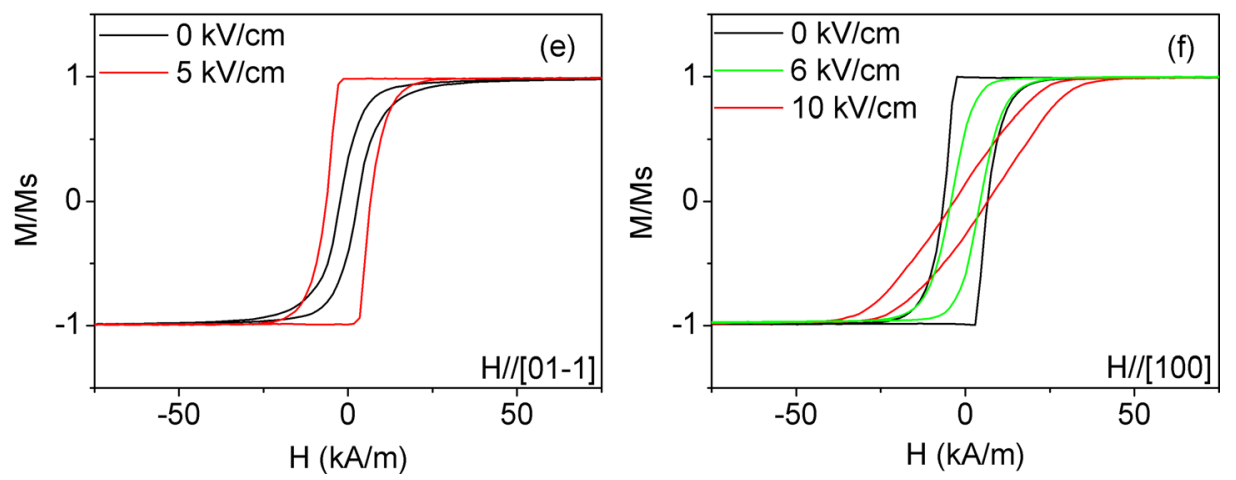

directions. The arrows indicate the direction of the E-field sweeping. The results along [010] are also plotted together for comparison. The opened symbols (square and circle) represent the as-grown $\mathrm{M}_{\mathrm{r}} / \mathrm{M}_{\mathrm{s}}$ along [010] and [100],

respectively. The as-grown $\mathrm{M}_{\mathrm{r}} / \mathrm{M}_{\mathrm{s}}$ along [100] and [010] are taken from magnetic hysteresis loops measured before any applied E-field. It is clear to see that the results between the two directions of [100] and [010] show an opposite variation
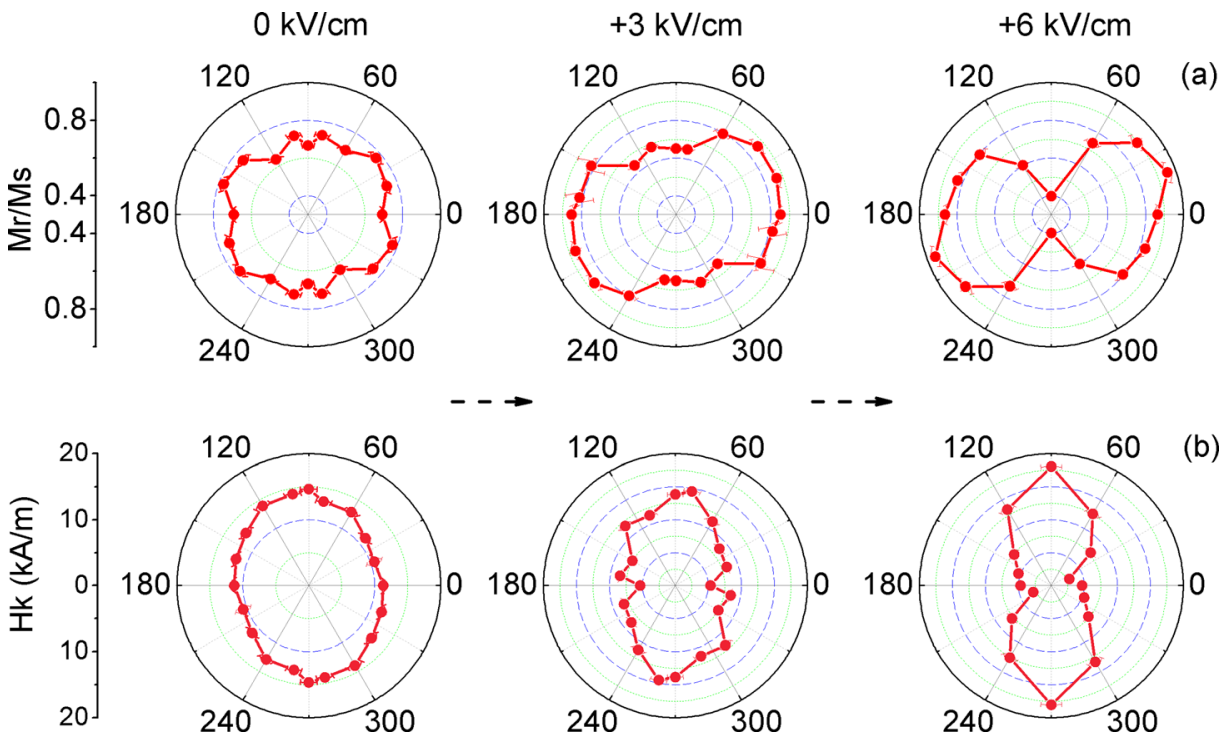

FIG. 4. The angular dependence of the $\mathrm{M}_{\mathrm{r}} / \mathrm{M}_{\mathrm{s}}$ (a) and $\mathrm{H}_{\mathrm{k}}$ (b) with the increasing applied E: $0 \mathrm{kV} / \mathrm{cm},+3 \mathrm{kV} / \mathrm{cm}$, and $+6 \mathrm{kV} / \mathrm{cm}$ in $65 \mathrm{~nm} \mathrm{CoFe} / 24 \mathrm{~nm}$ Metglas/(001) PMN-PT heterostructure. 


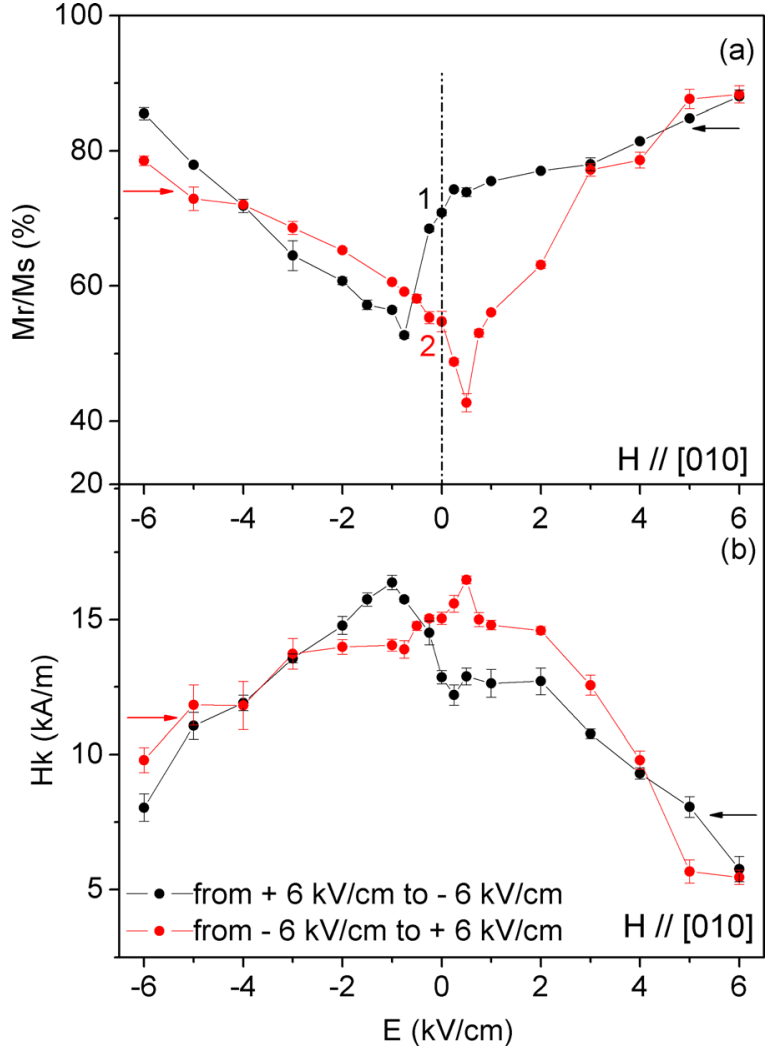

FIG. 5. Electrical dependence of the $\mathrm{M}_{\mathrm{r}} / \mathrm{M}_{\mathrm{s}}$ (a) and $\mathrm{H}_{\mathrm{k}}$ (b) along [010] with different E sweeping directions in $65 \mathrm{~nm} \mathrm{CoFe} / 24 \mathrm{~nm}$ Metglas/(001) PMNPT heterostructure. The arrows indicate the direction of the E-field sweeping.

tendency, which is consistent with previous reports. ${ }^{5,29,32}$ The positions of valleys and peaks along [100] and [010] are the same, with $+0.5 \mathrm{kV} / \mathrm{cm}$ in Fig. $6(\mathrm{a})$ and $-0.75 \mathrm{kV} / \mathrm{cm}$ in Fig. 6(b). In addition, it is noted that the value of $\mathrm{M}_{\mathrm{r}} / \mathrm{M}_{\mathrm{s}}$ does not return to the as-grown value after removing the E-field, but remains a permanent change in magnetization state and anisotropy, which suggests that the E-field creates two stable remaining strain states which are transferred to the bilayered magnetic films due to the elastic coupling.

A hysteresis loop of MR measured along [100] as a function of the applied E-field is demonstrated in Fig. 7. When the E-field changes from $-2 \mathrm{kV} / \mathrm{cm}$ to $1.75 \mathrm{kV} / \mathrm{cm}$ or from $-0.75 \mathrm{kV} / \mathrm{cm}$ to $-1.75 \mathrm{kV} / \mathrm{cm}$, the magnetization is along [100], while when the E-field changes from $6 \mathrm{kV} / \mathrm{cm}$ to $-0.75 \mathrm{kV} / \mathrm{cm}$ or from $1.75 \mathrm{kV} / \mathrm{cm}$ to $6 \mathrm{kV} / \mathrm{cm}$, the magnetization is along [010], as shown in Fig. 7. Based on the anisotropic magnetoresistance effect (AMR), when the magnetization is parallel to a test current, a low MR is measured, while when the magnetization is perpendicular to the test current, a high MR is measured. On the other hand, when a non-magnetic metal layer is introduced between the bilayered magnetic films, based on the GMR effect, the low MR is measured when magnetization in the free magnetic layer is parallel to that in the pinned magnetic layer, while the high MR is measured, when magnetization in free magnetic layer is anti-parallel to that in pinned magnetic layer. The parallel and anti-parallel magnetization between the free layer and the pinned layer is easy to achieve by

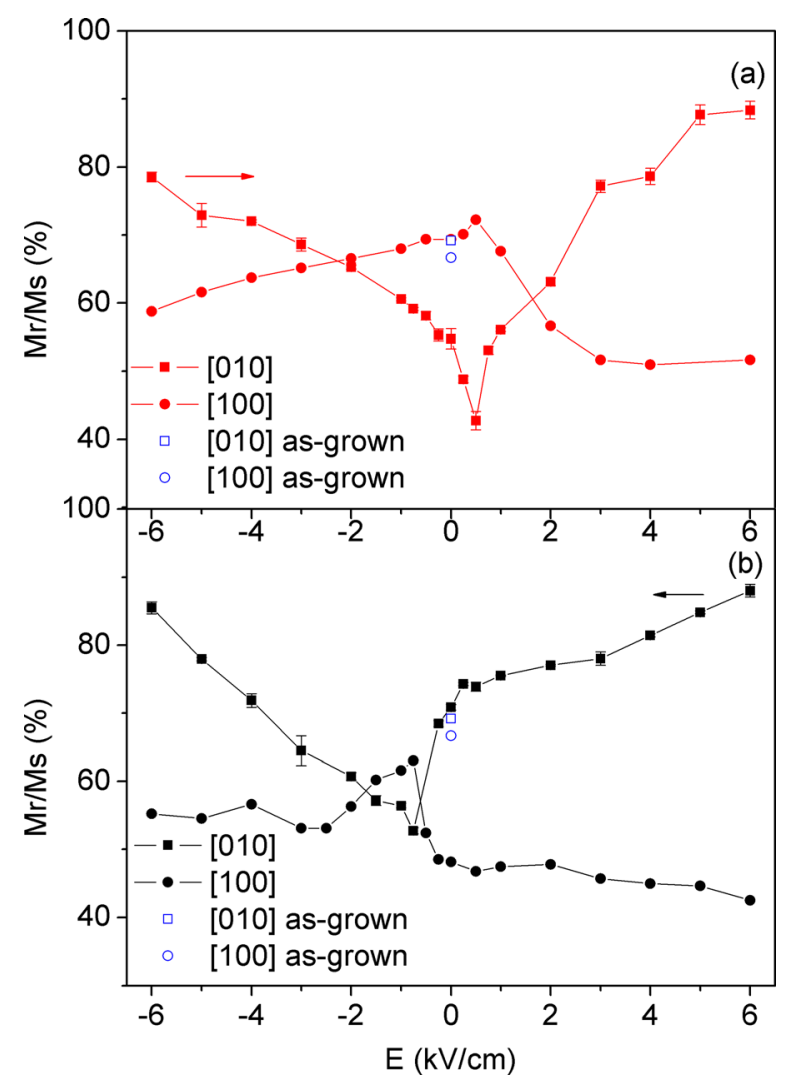

FIG. 6. Electrical dependence of the $\mathrm{M}_{\mathrm{r}} / \mathrm{M}_{\mathrm{s}}$ along [100] with different E-field sweeping directions in $65 \mathrm{~nm} \mathrm{CoFe} / 24 \mathrm{~nm}$ Metglas/(001) PMN-PT heterostructure. Those along [010] also were plotted together for the comparison. The arrows indicate the direction of the E-field sweeping: (a) from $-6 \mathrm{kV} / \mathrm{cm}$ to $+6 \mathrm{kV} / \mathrm{cm}$ and (b) from $+6 \mathrm{kV} / \mathrm{cm}$ to $-6 \mathrm{kV} / \mathrm{cm}$.

choosing ferromagnetic films with obvious different $\lambda$. In this study, we only focus on E-field controlled bilayered magnetic films.

In summary, strong ME coupling was observed in all these heterostructures based strain mediated mechanism. The giant ME coupling constant $\alpha=2.9 \times 10^{-6} \mathrm{~s} / \mathrm{m}$ was demonstrated in $30 \mathrm{~nm} \mathrm{CoFe} / 12 \mathrm{~nm}$ Metglas/(011) PMN-PT heterostructure due to the improved $\lambda$ and reduced magnetic layer thickness. The non-volatile magnetization change was shown

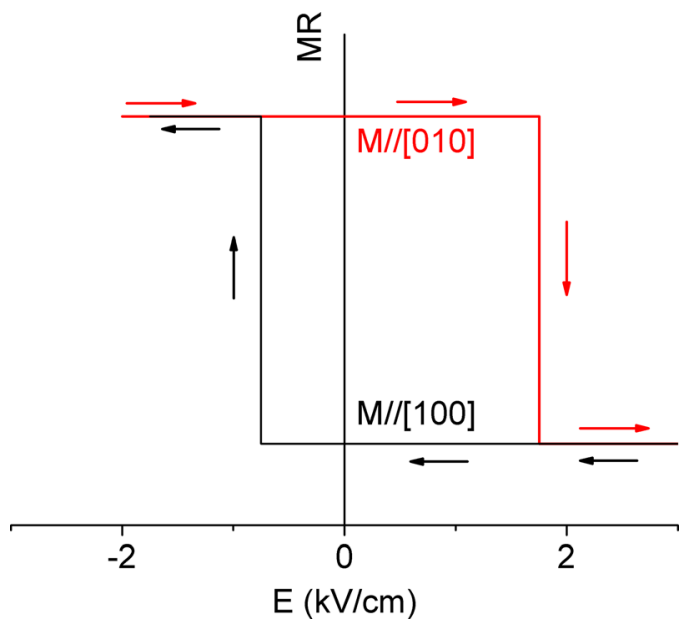

FIG. 7. A hysteresis loop of MR as a function of the applied E with magnetization change. 
in CoFe/Metglas/(001) PMN-PT heterostructure. Two new created bistable magnetization states could be reversibly switched by an E-field, while the as-grown state was permanently altered. Based on GMR or AMR, the MERAM memory cell was proposed for the fast, low-power, and highdensity information storage.

\section{ACKNOWLEDGMENTS}

This work was financially supported by a University of Sheffield Prize Scholarship.

${ }^{1}$ C. Israel, N. D. Mathur, and J. F. Scott, Nature Mater. 7, 93 (2008).

${ }^{2}$ C. Chappert, A. Fert, and F. N. Van Dau, Nature Mater. 6, 813 (2007).

${ }^{3}$ D. Barrionuevo, N. Ortega, A. Kumar, R. Chatterjee, J. F. Scott, and R. S. Katiyar, J. Appl. Phys. 114, 234103 (2013).

${ }^{4}$ M. Bibes and A. Barthélémy, Nature Mater. 7, 425 (2008).

${ }^{5}$ J. H. Park, Y. K. Jeong, S. Ryu, J. Y. Son, and H. M. Jang, Appl. Phys. Lett. 96, 192504 (2010)

${ }^{6}$ M. Liu, O. Obi, J. Lou, Y. J. Chen, Z. H. Cai, S. Stoute, M. Espanol, M. Lew, X. Situ, K. S. Ziemer, V. G. Harris, and N. X. Sun, Adv. Funct. Mater. 19, 1826 (2009).

${ }^{7}$ Y. Zhang, Z. G. Wang, Y. J. Wang, C. T. Luo, J. F. Li, and D. Viehland, J. Appl. Phys. 115, 084101 (2014).

${ }^{8}$ M. Liu, Z. Y. Zhou, T. X. Nan, B. M. Howe, G. J. Brown, and N. X. Sun, Adv. Mater. 25, 1435 (2013).

${ }^{9}$ J. Wang, J. Hu, H. Wang, H. Jiang, Z. Wu, J. Ma, X. Wang, Y. Lin, and C. W. Nan, J. Appl. Phys. 107, 083901 (2010).

${ }^{10}$ J. J. Yang, Y. G. Zhao, H. F. Tian, L. B. Luo, H. Y. Zhang, Y. J. He, and H. S. Luo, Appl. Phys. Lett. 94, 212504 (2009).

${ }^{11}$ Y. Chen, J. Gao, T. Fitchorov, Z. Cai, K. S. Ziemer, C. Vittoria, and V. G. Harris, Appl. Phys. Lett. 94, 082504 (2009).

${ }^{12}$ J. W. Lee, S. C. Shin, and S. K. Kim, Appl. Phys. Lett. 82, 2458 (2003).

${ }^{13}$ M. Liu, O. Obi, Z. Cai, J. Lou, G. Yang, K. S. Ziemer, and N. X. Sun, J. Appl. Phys. 107, 073916 (2010).

${ }^{14}$ W. Eerenstein, N. D. Mathur, and J. F. Scott, Nature 442, 759 (2006).
${ }^{15}$ N. Ortega, A. Kumar, R. S. Katiyar, and J. F. Scott, Appl. Phys. Lett. 91, 102902 (2007).

${ }^{16}$ W. Eerenstein, F. D. Morrison, J. Dho, M. G. Blamire, J. F. Scott, and N. D. Mathur, Science 307, 1203a (2005).

${ }^{17}$ N. Ortega, A. Kumar, J. F. Scott, D. B. Chrisey, M. Tomazawa, S. Kumari, D. G. B. Diestra, and R. S. Katiyar, J. Phys.: Condens. Matter 24, 445901 (2012).

${ }^{18}$ M. Liu, S. D. Li, O. Obi, J. Lou, S. Rand, and N. X. Sun, Appl. Phys. Lett. 98, 222509 (2011).

${ }^{19}$ A. Brandlmaier, S. Geprägs, G. Woltersdorf, R. Gross, and S. T. B. Goennenwein, J. Appl. Phys. 110, 043913 (2011).

${ }^{20}$ Z. Li, J. Wang, Y. Lin, and C. W. Nan, Appl. Phys. Lett. 96, 162505 (2010).

${ }^{21}$ T. Wu, A. Bur, P. Zhao, K. P. Mohanchandra, K. Wong, K. L. Wang, C. S. Lynch, and G. P. Carman, Appl. Phys. Lett. 98, 012504 (2011).

${ }^{22}$ S. W. Yang, R. C. Peng, T. Jiang, Y. K. Liu, L. Feng, J. J. Wang, L. Q. Chen, X. G. Li, and C. W. Nan, Adv. Mater. 26, 7091 (2014).

${ }^{23}$ Y. Chen, T. Fitchorov, Z. Cai, K. S. Ziemer, C. Vittoria, and V. G. Harris, J. Phys. D: Appl. Phys. 43, 155001 (2010).

${ }^{24}$ V. A. Vas'ko, J. O. Rantschler, and M. T. Kief, IEEE Trans. Magn. 40, 2335 (2004)

${ }^{25}$ S. Das, A. Herklotz, E. Pippel, E. J. Guo, D. Rata, and K. Dörr, Phys. Rev. B 91, 134405 (2015)

${ }^{26}$ P. Han, W. Yan, J. Tian, X. Huang, and H. Pan, Appl. Phys. Lett. 86, 052902 (2005).

${ }^{27}$ A. Javed, N. A. Morley, and M. R. J. Gibbs, J. Magn. Magn. Mater. 321, 2877 (2009).

${ }^{28}$ S. Kotapati, A. Javed, N. Reeves-Mclaren, M. R. J. Gibbs, and N. A. Morley, J. Magn. Magn. Mater. 331, 67 (2013).

${ }^{29}$ J. H. Kim, K. S. Ryu, J. W. Jeong, and S. C. Shin, Appl. Phys. Lett. 97, 252508 (2010).

${ }^{30}$ W. Eerenstein, M. Wiora, J. L. Prieto, J. F. Scott, and N. D. Mathur, Nature Mater. 6, 348 (2007).

${ }^{31}$ Y. Chen, T. Fitchorov, C. Vittoria, and V. G. Harris, Appl. Phys. Lett. 97, 052502 (2010).

${ }^{32}$ C. Thiele, K. Dörr, O. Bilani, J. Rödel, and L. Schultz, Phys. Rev. B 75, 054408 (2007). 